\title{
INDUCTIVE DECISION TREE ANALYSIS OF THE VALIDITY RANK OF CONSTRUCTION PARAMETERS OF INNOVATIVE GEAR PUMP AFTER TOOTH ROOT UNDERCUTTING
}

\author{
A. DEPTUŁA* and M.A. PARTYKA \\ Department of Knowledge Engineering \\ Faculty of Production Engineering and Logistics \\ Opole University of Technology \\ 75 Ozimska Street, 45-233 Opole, POLAND \\ E-mail: a.deptula@po.opole.pl
}

\begin{abstract}
The article presents an innovative use of inductive algorithm for generating the decision tree for an analysis of the rank validity parameters of construction and maintenance of the gear pump with undercut tooth. It is preventet an alternative way of generating sets of decisions and determining the hierarchy of decision variables to existing the methods of discrete optimization.
\end{abstract}

Key words: inductive decision tree, gear pump, tooth root undercutting, validity rank of the construction parameter, optimization.

\section{Introduction}

Gear pump constructions have been used and developed for over 400 years. Johannes Kepler created the first gear unit in 1604. The primary application of the patented solution at that time was to pump water in dehydrated mines [1, 2-9]. The valveless and self-priming gear construction resistant to numerous contaminations present in the water removed from shaft wells very quickly replaced hard to use piston pumps used at that time. The author of this solution saw a wider application of his invention. His ideas could be used to remove bilge water on ships, force the water flow in park and garden fountains but also to compress air in the construction of blowers and exhausters.

In 1636 Daniel Schwenter in his paper entitled Deliciae mathematicae oder mathematische und philosophische Erquickstuden presented a complete description of an external gear pump operation with the construction sketch. Particular attention was paid in this description to keeping the internal tightness "teeth of one of the wheels attack teeth of the second one and they do it so precisely that neither air nor water can go through the hull or in the middle, between the co-operating teeth or sides because there is no space between wheels and casing walls". This is why in the 17th century much attention was paid to keeping appropriate dimension tolerance of co-operating displacement elements with the casing. The improvement of internal tightness is connected with the minimization of energy losses, increasing the transferred power and energy efficiency of the generator [10 - 14]. This article relates to the problem of optimizing the gear pump after tooth root undercutting and, in particular, the determination of importance rank design operating parameters. This publication contains graphic applications decision-making structures and also closing test cycle specific for innovative gear pump.

\footnotetext{
* To whom correspondence should be addressed
} 


\section{The research object}

\subsection{Measuring rig}

The static characteristics of the pump with tooth root relief and its circumferential damping were determined using the rig shown in Fig.1. In the rig, tested pump 1 is driven by $100 \mathrm{~kW}$ DC motor 2 working in tandem with SCR control system 20. The Pxob-94a motor and the DSI-0360/MN-503 thyristor control system make possible the smooth changing of pump rotational speed from 0 to $2000 \mathrm{rpm}$.

Preliminary pressure pump 3 and tested pump 1 are protected by safety valves 7 and 8 . Tested pump 1 is loaded through throttle valve 10 . The pump's actual delivery $Q_{r z}$ is measured by PT-M1 turbine flowmeter 16 with a PT15-100 flow sensor with a measuring range of $0-100 \mathrm{dm}^{3} / \mathrm{min}$. Instantaneous flow rates are recorded using a METEX microammeter type M-3650B. Pump output torque $M$ is measured by Mt1000 torque sensor 21 with a measuring range of $0-000 \mathrm{Nm}$ and a Beta 2002 recording system. The pump's number of revolutions $n$ is controlled on the driving motor shaft by a measuring system consisting of a photocell and digital counter 22. For this purpose a disc with holes in it is mounted on the motor shaft. There is a light source on one side of the disc with holes and a photocell on its other side. The photocell counts the number of electronic pulses dependent on the shaft rotational speed. This set is used solely to fix the prescribed speed of the driving system. Temperature $t$ of the liquid in the tank was measured by a set of thermistors (sensor PU 391/2 and meter PU 381/1).
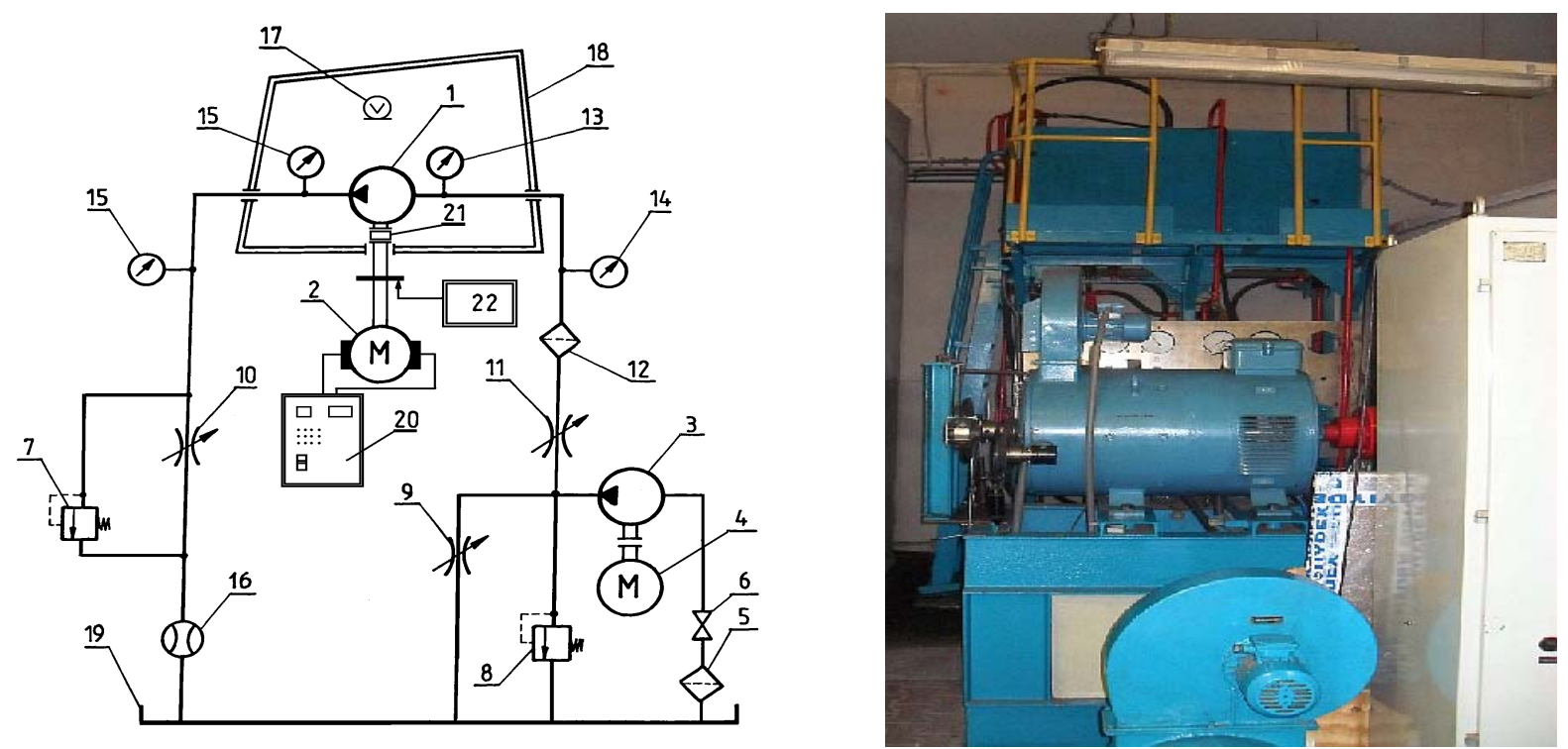

Fig.1. Schematic of test rig: 1-tested pump, 2-driving DC motor, 3-feed pump, 4-AC motor, 5-suction filter, 6-cut-off valve, 7,8-safety valves, 9,10,11-cut-off valve, 12-drain filter, 13,14-manovacuometer 15pressure gauge, 16-flowmeter with microammeter, 17-measuring microphones, 18-sound chamber, 19-tank, 20-electronic rpm adjustment system, 21-torque sensor with recorder, 22-photocell with measuring counter.

The tested prototype unit was designed in-house and manufactured by the Hydraulic Pumps Manufacturing Company Ltd. in Wrocław. The pump was designed having in mind the technological capacities of this company. The novelty of the prototype pump consists in the modification of the involute 
profile in its upper part through the so-called tooth root relief (undercut). Figure 2 shows a pump in the acoustic chamber.

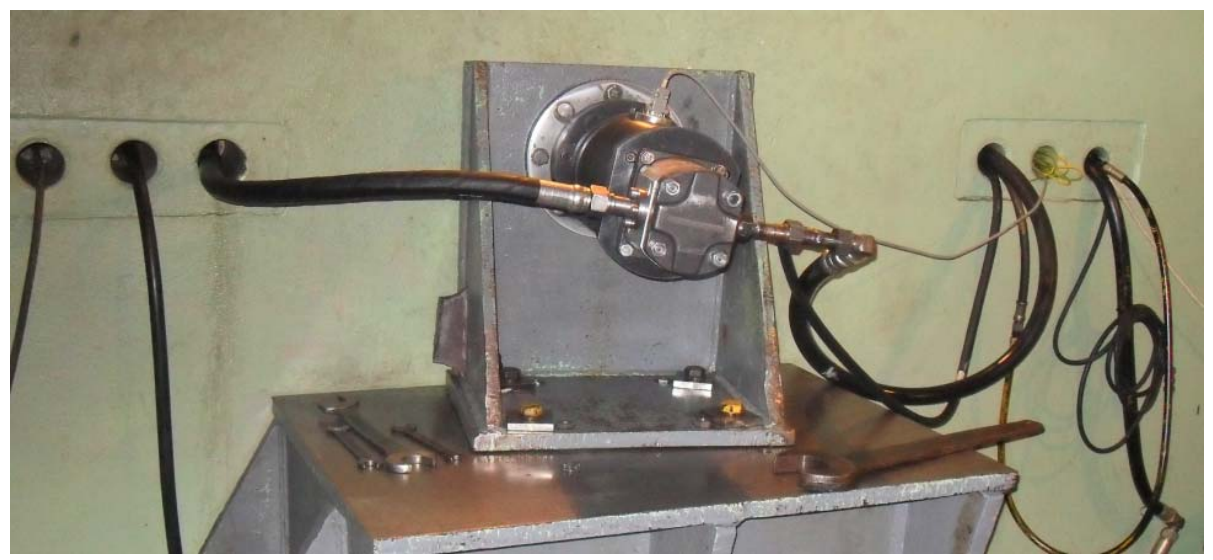

Fig.2. Gear pump in the acoustic chamber during testing.

\section{Discrete optimization of a gear pump after tooth root undercutting}

In this study, functions: $\eta_{v}, \eta_{h m}, \eta_{c}$ are the criterion functions of purpose whereas parameters $n, p_{t}$, $Q_{1 z}, M$ are decision variables. Such an approach makes sense from the point of view of using a given gear pump in different systems and determining calculation divergence because of various algorithms of the gear pump design [7], e.g., determining the maximum volumetric efficiency with permissible hydraulic and mechanical efficiency and determining the maximum total efficiency.

A gear pump optimization requires calculating volumetric, hydraulic and mechanical, as well as total efficiency. The pump efficiency optimization can be multi-criteria or mono-criterion [15-23]. Assuming that the total pump efficiency is the function of purpose and the parameters we are looking for are values of construction and/or exploitation parameters, then optimization can be made separately for construction and exploitation parameters looking for the maximum efficiency value. There are already elaborations of a discrete optimization of a gear pump after tooth root undercutting with the application of graphic decision structures. They include the application of ordinary logic multi-valued decision trees [7], logic complex decision trees [24] and game structures from signal-flow graphs [25]. All elaborated methods confirm that it is very good to apply separate tools of this type and at the same time each of the applied methods has individual features and properties from the point of view of the construction of the integrated decision system. Each method is based on results of measurements of static characteristics of an experimental pump after tooth root undercutting presented in Tab.1. These results were obtained after a test of the innovative gear pump.

In addition, Tab. 1 presents the readings of arithmetic and logical values of determined parameters and the function of the objective when coding by means of the method of ordinary multi-valued logic trees and complex logic decision trees. 
Table 1. Arithmetic and logic values of the agreed parameters and the function of purpose.

\begin{tabular}{|c|c|c|c|c|c|c|c|c|c|c|c|}
\hline & & Hydraul & measur & hent res & & & & & & $\mathrm{fth}$ & \\
\hline & & & & & & & & & & & $*$ \\
\hline $\left.\begin{array}{c}n \\
{[\mathrm{rpm}]}\end{array}\right]$ & $\begin{array}{c}p_{t} \\
{[\mathrm{Mpa}]}\end{array}$ & $\begin{array}{c}Q_{r z} \\
{[1 / \mathrm{min}]}\end{array}$ & $\begin{array}{c}\boldsymbol{M} \\
{[\mathrm{Nm}]}\end{array}$ & $\begin{array}{c}\eta_{v} \\
{[\%]}\end{array}$ & $\begin{array}{c}\eta_{h m} \\
{[\%]}\end{array}$ & $\begin{array}{c}\eta_{c} \\
{[\%]}\end{array}$ & $n$ & $p_{t}$ & $Q_{r z}$ & $M$ & $M$ \\
\hline 500 & $\approx 0$ & 21.1 & 2.0 & 94.6 & 0.0 & 0.0 & & 0 & & 0 & 0 \\
\hline & 5 & 20.5 & 36.0 & 92.1 & 98.0 & 90.3 & & 1 & & 0 & 1 \\
\hline & 10 & 20.3 & 77.0 & 91.3 & 91.8 & 83.8 & & 2 & & 1 & 2 \\
\hline & 15 & 20.2 & 116.0 & 90.9 & 91.5 & 83.1 & 0 & 3 & 0 & 1 & 3 \\
\hline & 20 & 20.2 & 156.0 & 90.9 & 90.7 & 82.4 & 0 & 4 & 0 & 2 & 4 \\
\hline & 25 & 20.5 & 200.0 & 92.1 & 88.5 & 81.5 & & 5 & & 3 & 5 \\
\hline & 28 & 20.6 & 218.0 & 92.5 & 90.9 & 84.1 & & 6 & & 3 & 6 \\
\hline & 30 & 20.7 & 236.0 & 93.0 & 90.0 & 83.6 & & 7 & & 3 & 7 \\
\hline 800 & $\approx 0$ & 34.9 & 2.0 & 98.0 & 0.0 & 0.0 & & 0 & & 0 & 0 \\
\hline & 5 & 34.7 & 38.0 & 97.5 & 92.8 & 90.5 & & 1 & & 0 & 1 \\
\hline & 10 & 34.3 & 78.0 & 96.2 & 90.6 & 87.2 & & 2 & & 1 & 2 \\
\hline & 15 & 34.2 & 118.0 & 96.0 & 89.9 & 86.3 & 1 & 3 & 1 & 1 & 3 \\
\hline & 20 & 34.1 & 160.0 & 95.7 & 88.4 & 84.6 & 1 & 4 & $I$ & 2 & 4 \\
\hline & 25 & 34.5 & 202.0 & 97.0 & 87.6 & 85.0 & & 5 & & 3 & 5 \\
\hline & 28 & 34.7 & 224.0 & 97.5 & 88.5 & 86.3 & & 6 & & 3 & 6 \\
\hline & 30 & 34.8 & 240.0 & 97.8 & 88.5 & 86.5 & & 7 & & 3 & 7 \\
\hline 1000 & $\approx 0$ & 44.5 & 2.2 & 99.9 & 0.0 & 0.0 & & 0 & & $\overline{0}$ & 0 \\
\hline & 5 & 44.1 & 38.0 & 99.1 & 92.8 & 92.0 & & 1 & & 0 & 1 \\
\hline & 10 & 43.9 & 82.0 & 98.7 & 86.2 & 85.1 & & 2 & & 1 & 2 \\
\hline & 15 & 43.4 & 124.0 & 97.4 & 85.6 & 83.4 & 2 & 3 & 2 & 1 & 3 \\
\hline & 20 & 43.4 & 168.0 & 97.4 & 84.2 & 82.1 & 2 & 4 & 2 & 2 & 4 \\
\hline & 25 & 43.4 & 208.0 & 97.4 & 85.1 & 82.9 & & 5 & & 3 & 5 \\
\hline & 28 & 43.4 & 234.0 & 97.4 & 84.7 & 82.5 & & 6 & & 3 & 6 \\
\hline & 30 & 43.3 & 249.0 & 97.2 & 85.3 & 82.9 & & 7 & & 3 & 7 \\
\hline 1500 & $\approx 0$ & 67.3 & 6.0 & 100.9 & 0.0 & 0.0 & & 0 & & 0 & 0 \\
\hline & 5 & 66.8 & 42.0 & 100.0 & 84.0 & 84.0 & & 1 & & 0 & 1 \\
\hline & 10 & 66.5 & 84.0 & 99.6 & 84.1 & 83.8 & & 2 & & 1 & 2 \\
\hline & 15 & 66.1 & 125.0 & 99.1 & 84.9 & 84.1 & 3 & 3 & & 1 & 3 \\
\hline & 20 & 65.5 & 172.0 & 98.1 & 82.3 & 80.7 & 3 & 4 & 3 & 2 & 4 \\
\hline & 25 & 65.7 & 210.0 & 98.4 & 84.2 & 82.9 & & 5 & & 3 & 5 \\
\hline & 28 & 65.6 & 235.0 & 98.2 & 84.3 & 82.8 & & 6 & & 3 & 6 \\
\hline & 30 & 65.5 & 255.0 & 98.1 & 83.3 & 81.7 & & 7 & & 3 & 7 \\
\hline 2000 & $\approx 0$ & 89.3 & 8.0 & 100.3 & 0.0 & 0.0 & & 0 & & $\overline{0}$ & 0 \\
\hline & 5 & 89.0 & 47.0 & 100.0 & 75.0 & 75.0 & & 1 & & 0 & 1 \\
\hline & 10 & 88.3 & 94.0 & 99.3 & 75.2 & 74.6 & & 2 & & 1 & 2 \\
\hline & 15 & 88.0 & 138.0 & 98.8 & 76.9 & 76.0 & 1 & 3 & 1 & 2 & 3 \\
\hline & 20 & 87.6 & 182.0 & 98.4 & 77.8 & 76.5 & 4 & 4 & 4 & 2 & 4 \\
\hline & 25 & 88.0 & 214.0 & 98.8 & 82.7 & 81.7 & & 5 & & 3 & 5 \\
\hline & 28 & 87.9 & 241.0 & 98.7 & 82.2 & 81.2 & & 6 & & 3 & 6 \\
\hline & 30 & 87.8 & 259.0 & 98.6 & 82.0 & 80.9 & & 7 & & 3 & 7 \\
\hline
\end{tabular}

\footnotetext{
*- encoding parameter $M$ for the complex trees and complexity coefficient.
} 


\subsection{Application of logic, complex multi-valued logic trees and complexity coefficient}

While looking for optimal function values $\eta_{v}, \eta_{h m}, \eta_{c}$, the following arithmetic scopes of changes have been adopted: $\eta_{v} \geq 0.96 ; \eta_{h m} \geq 0.89 ; \eta_{c} \geq 0.86$. Arithmetic values of analysed parameters have been chosen in order to make an analysis in accordance Tab.1. These values were coded by means of logic decision variables for the needs of logic decision trees [7].

$$
\begin{aligned}
& n=500[\mathrm{rpm}] \sim 0 ; n=800[\mathrm{rpm}] \sim 1 ; n=1000[\mathrm{rpm}] \sim 2 ; n=1500[\mathrm{rpm}] \sim 3 ; n=2000[\mathrm{rpm}] \sim 4 ; \\
& p_{t}=\approx 0[\mathrm{MPa}] \sim 0 ; \quad p_{t}=5[\mathrm{MPa}] \sim 1 ; p_{t}=10[\mathrm{MPa}] \sim 2 ; \quad p_{t}=15[\mathrm{MPa}] \sim 3 ; p_{t}=20[\mathrm{MPa}] \sim 4 ;
\end{aligned}
$$$$
p_{t}=25[\mathrm{MPa}] \sim 5 ; p_{t}=28[\mathrm{MPa}] \sim 6 ; p_{t}=30[\mathrm{MPa}] \sim 7 ;
$$

$Q_{r z} \in\langle 20,2 ; 21,1\rangle[\mathrm{l} / \mathrm{min}] \sim 0 ; Q_{r z} \in\langle 34,2 ; 34,9\rangle[\mathrm{l} / \mathrm{min}] \sim 1 ; Q_{r z} \in\langle 43,3 ; 44,5\rangle[\mathrm{l} / \mathrm{min}] \sim 2 ;[\mathrm{l} / \mathrm{min}] \sim 3 ;$

$Q_{r z} \in\langle 87,6 ; 89,3\rangle[\mathrm{l} / \mathrm{min}] \sim 4 ; M \in\langle 2,0 ; 47,0\rangle[\mathrm{Nm}] \quad \sim \quad 0 ; \quad M \in\langle 77,0 ; 125,0\rangle[\mathrm{Nm}] \quad \sim \quad 1 ;$ $M \in\langle 138,0 ; 182,0\rangle[\mathrm{Nm}] \sim 2 ; M \in\langle 200,0 ; 259,0\rangle[\mathrm{Nm}] \sim 3$;

In the case of multi- valued complex decision trees, the moment $M$ was coded as follows [25]. $M \in\langle 2,0 ; 8,0\rangle[\mathrm{Nm}] \sim 0 ; M \in\langle 36,0 ; 47,0\rangle[\mathrm{Nm}] \sim 1 ; M \in\langle 77,0 ; 94,0\rangle[\mathrm{Nm}] \sim 2 ; M \in\langle 116,0 ; 138,0\rangle[\mathrm{Nm}] \sim$ 3; $M \in\langle 156,0 ; 182,0\rangle \quad[N m] \sim 4 ; \quad M \in\langle 200,0 ; 214,0\rangle[N m] \sim \quad 5 ; \quad M \in\langle 210,0 ; 241,0\rangle[N m] \sim 6 ;$ $M \in\langle 236,0 ; 259,0\rangle[N m] \sim 7$;

Table 2 summarizes the assessment of the validity of the rank of the three methods for $n, Q_{z}, p_{t}, M$.

Table 2 . The validity rank of the three methods for $n, Q_{z z}, p_{t}, M$ and efficiency: $\eta_{c}, \eta_{h m}, \eta_{v}$

\begin{tabular}{|c|c|c|c|c|c|}
\hline \multicolumn{2}{|c|}{ Applied method discrete } \\
\hline $\begin{array}{c}\text { Multi- valued logic decision } \\
\text { trees }\end{array}$ & \multicolumn{2}{c|}{$\begin{array}{c}\text { Multi- valued complex } \\
\text { decision trees }\end{array}$} & $\begin{array}{c}\text { Complex coefficient of } \\
\text { complexity for game-tree } \\
\text { structures }\end{array}$ \\
\hline Rank validity & Efficiency & Rank validity & Efficiency & Rank validity & Efficiency \\
\hline $\begin{array}{c}p, Q \wedge n, M \\
p, M, Q \wedge n\end{array}$ & $\eta_{c}$ & $M \wedge p, Q \wedge n$ & $\eta_{c}$ & $p, M, Q \wedge n$ & $\eta_{c}$ \\
\hline$p, M, Q \wedge n$ & $\eta_{h m}$ & $M \wedge p, Q \wedge n$ & $\eta_{h m}$ & $M, p, Q \wedge n$ & $\eta_{h m}$ \\
\hline$Q \wedge n, p, M$ & $\eta_{v}$ & $M \wedge p, Q \wedge n$ & $\eta_{\mathrm{v}}$ & $M, p, Q \wedge n$ & $\eta_{v}$ \\
\hline
\end{tabular}

\section{Inductive decision tree analysis of the validity rank of construction parameters}

In a decision tree, nodes store tests checking values of example attributes and leaves store categories assigned to them. For each of possible test results, there is one branch coming from a node to a subtree. In this way, it is possible to represent any attributes of the hypothesis admissible for a given set. A decision tree is a structure which has ordinary properties of trees in the meaning assigned to the tree in information technology, so it is a structure composed of nodes from which branches come to other nodes or leaves. It is convenient to define tree structures in a recursive way:

1. The leaf containing any category label $d \in C$ is a decision tree.

2. For any node of $n$ decision tree, by $t_{n}$ we mean a test connected with it, and for each of its possible results $r \in R_{t}$ by $n[r]$ node or child leaf, to which the $\mathrm{n}$ branch related to the $\mathrm{r}$ result leads from the node. 


\subsection{The notation of decision trees}

For any example $x \in X$ there is exactly one leaf of a decision tree $T$ connected with it which is designated as $l_{T, x}$, and a set of nodes corresponding to it on different levels, which is designated as $N_{T, x}$. For any node $n \in N_{T}$ of the tree $T$ and a set of examples $P \subseteq X$ there is a subset connected with $n$ designated as $P_{\mathrm{T}, \mathrm{x}}$ and analogically, for any leaf $l \in L_{T}$ there is a set of examples from $P$ and $P_{T, l}$ corresponding to it. The following dependences exist:

$$
\begin{aligned}
& P_{T, n}=\left\{x \in P \mid n \in N_{T, x}\right\}, \\
& P_{T, l}=\left\{x \in P \mid l \in l_{T, x}\right\} .
\end{aligned}
$$

The notation described above is presented in Fig.3.

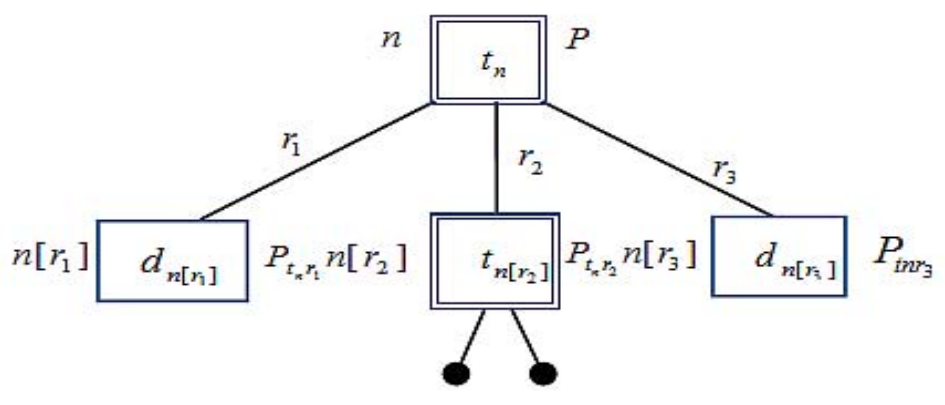

Fig.3. A sample query "query-by-example" to the decision-making system.

Entropy is the criterion making it possible to choose an attribute used for the tree development. It is a certain measure of information included in the phenomenon which in an accidental way can take $n$-states. It also designates the average value of the amount of information necessary to ensure the fact that a given phenomenon adopts one of the $n$ available states.

Information included in the set of training examples is equal to

$$
I(E)=-\sum_{i=1}^{|E|} \frac{\left|E_{i}\right|}{|E|} \cdot \log _{2}\left(\frac{\left|E_{i}\right|}{|E|}\right)
$$

where:

$E$ - the set of training examples

$\left|E_{i}\right|$ - the number of examples which describe $i$-th object

$|E|$ - the number of examples in the training set $E$

The expected value of information after the division of the set of examples $E$ into subsets $E^{(m)}, m=1, \ldots,\left|V_{a}\right|$, for which the attribute $a$ has the value $V_{m}$, determined as [17]

$$
I(E, a)=\sum_{m=1, K,\left|V_{a}\right|, E^{(m)}=\varnothing} \frac{\left|E^{(m)}\right|}{|E|} \cdot I\left(E^{(m)}\right)
$$


where:

$\left|E^{(m)}\right|$ - the number of examples after the division of the set $E$ in relation to the value $\mathrm{m}$ of a given attribute

$|E|$ - the number of examples in the training set $E$.

\subsection{The classification of validity rank of the construction parameters with the application of the DeTreex module}

The DeTreex module has been used in the classification of validity rank of the construction parameters and it makes it possible to form decision trees. In the described system, the module forming the decision tree requires an appropriate data preparation. In order to achieve it, a single text file with .lrn file extension has been prepared. Attributes and examples are set in columns.

Classification by means of induction trees has been made separately for volumetric efficiency $\eta_{v}$, mechanical efficiency $\eta_{h m}$ and total efficiency $\eta_{c}$ as output attributes (wy): As input attributes (we), values corresponding to the respective values of the symbolic of arithmetic parameters : $n, Q_{r z}, p_{t}$ and $M$. The algorithm uses an inductive symbolic values. These values were coded by means of induction decision variables:

$n=500[\mathrm{rpm}] \sim \mathrm{An} ; n=800[\mathrm{rpm}] \sim \mathrm{Bn} ; n=1000[\mathrm{rpm}] \sim \mathrm{Cn} ; n=1500[\mathrm{rpm}] \sim \mathrm{Dn} ; n=2000[\mathrm{rpm}] \sim \mathrm{En} ;$ $p_{t}=\approx 0[\mathrm{MPa}] \sim \mathrm{Apt} ; p_{t}=5[\mathrm{MPa}] \sim \mathrm{Bpt} ; p_{t}=10[\mathrm{MPa}] \sim \mathrm{Cpt} ; p_{t}=15[\mathrm{MPa}] \sim \mathrm{Dpt} ; p_{t}=20[\mathrm{MPa}] \sim \mathrm{Ept} ;$ $p_{t}=25[\mathrm{MPa}] \sim \mathrm{Fpt} ; p_{t}=28[\mathrm{MPa}] \sim \mathrm{Gpt} ; p_{t}=30[\mathrm{MPa}] \sim \mathrm{Hpt} ; Q_{r z} \in\langle 20,2 ; 21,1\rangle[1 / \mathrm{min}] \sim \mathrm{AQ}_{\mathrm{rz}} ;$ $Q_{r z} \in\langle 34,2 ; 34,9\rangle[1 / \mathrm{min}] \sim \mathrm{BQ}_{\mathrm{rz}} ; Q_{r z} \in\langle 43,3 ; 44,5\rangle[1 / \mathrm{min}] \sim \mathrm{DQ}_{\mathrm{rz}} ;[1 / \mathrm{min}] \sim 3 ; Q_{r z} \in\langle 87,6 ; 89,3\rangle[1 / \mathrm{min}] \sim$ $\mathrm{EQ}_{\mathrm{rz}} ; \quad M \in\langle 2,0 ; 47,0\rangle[\mathrm{Nm}] \sim \mathrm{AM} ; \quad M \in\langle 77,0 ; 125,0\rangle[\mathrm{Nm}] \sim \mathrm{BM} ; \quad M \in\langle 138,0 ; 182,0\rangle[\mathrm{Nm}] \sim \mathrm{CM}$; $M \in\langle 200,0 ; 259,0\rangle[\mathrm{Nm}] \sim \mathrm{DM}$;

Figure 4 shows a fragment of a file learning module DeTreex.

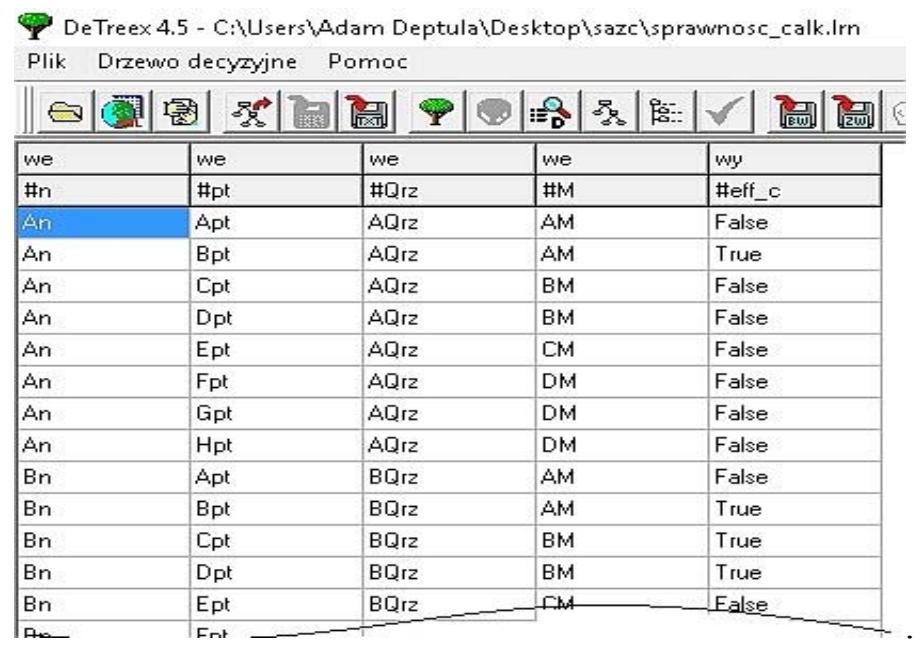

Fig.4. Sample file learner .lrn.

Then they generated three inductive decision trees for each efficiency: $\eta_{v}, \eta_{h m}, \eta_{c}$ (Figs 5-7). 


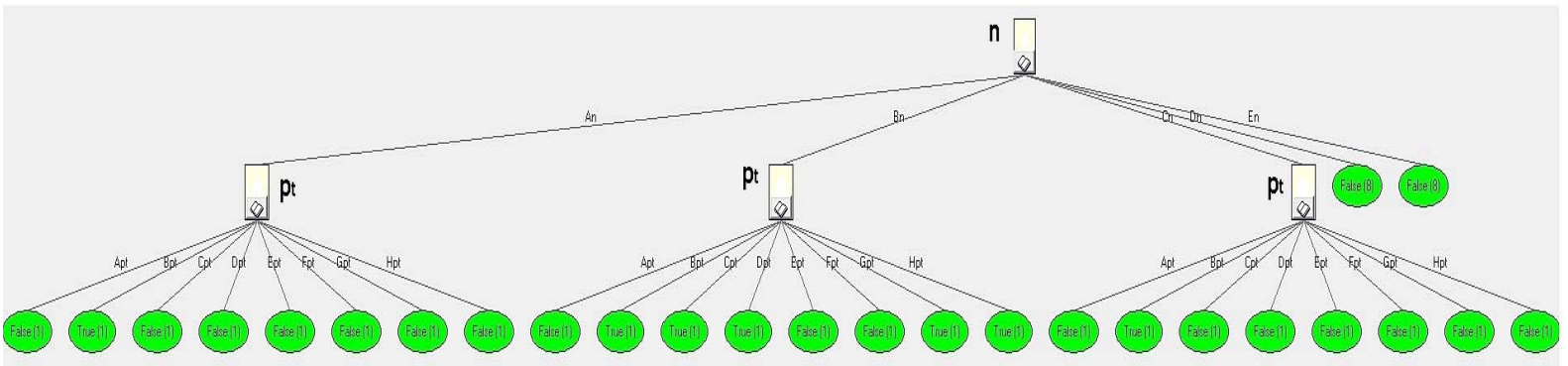

Fig.5. Inductive decision tree system DeTreex for efficiency $\eta_{c}$.

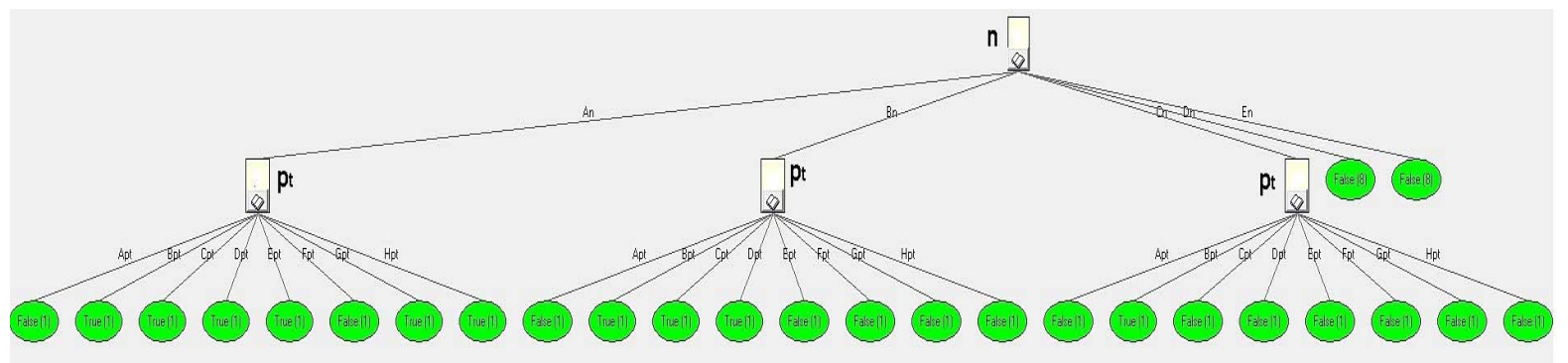

Fig.6. Inductive decision tree system DeTreex for efficiency $\eta_{h m}$.

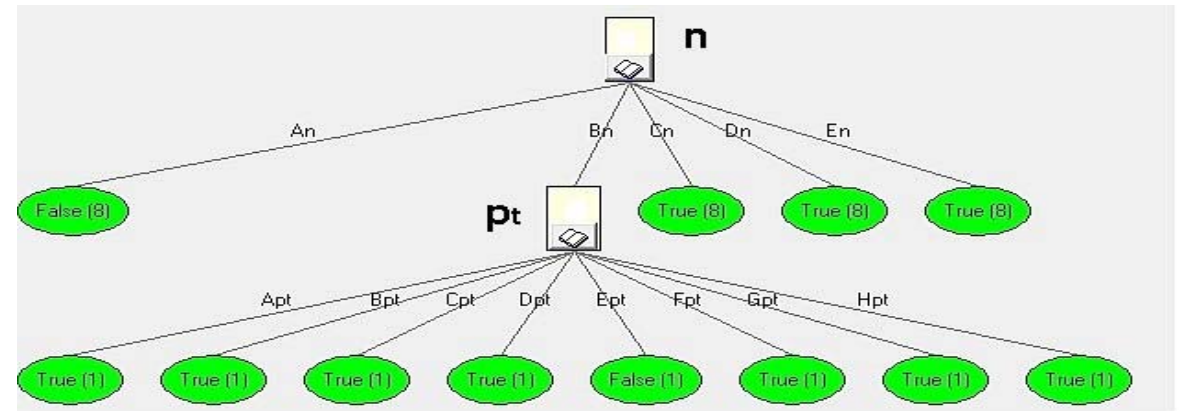

Fig.7. Inductive decision tree system DeTreex for efficiency $\eta_{v}$.

\section{Conclusions}

In a decision tree, nodes store tests checking values of example attributes and leaves store categories assigned to them. For each of possible test results, there is one branch coming from a node to a subtree. In this way, it is possible to represent any attributes of the hypothesis admissible for a given set. All operations were made in real time during normal exploitation of the gear pump. The induction tree determines the degree of importance of the attribute from the most important one placed in the root. The most important parameters are $n$ and $p_{t}$. In the case of multi- valued trees, the most important parameters are $n$ and $Q_{r z}$ treated as one substitute variable and the moment $M$. With the mechanical efficiency $\eta_{h m}$ and the volumetric efficiency $\eta_{w}$ there are single optimum multi-valued logic trees. In the case of the mechanical efficiency $\eta_{h m}$ the most important parameters are $n$ and $Q_{z z}$, and in the case of the volumetric efficiency $\eta_{v}$ - the moment $M$. In complex optimum decision trees, the most important variable in the root was the decision variable $Q \wedge n$. In papers $[24,25]$ a complex complexity coefficient $L^{K}$ was used in the description of multi-valued logic 
trees. Optimal complex logic trees $Q \wedge n$ were identically determined with combined and separable parameters $p$ and $M$. In a further step, we should increase the coding decision variables for tree induction. Then the validity rank is to be the same as in the previous methods. The game structure describes a space of possible solutions in order to find optimum objective functions [26, 27, 28].

\section{Nomenclature}

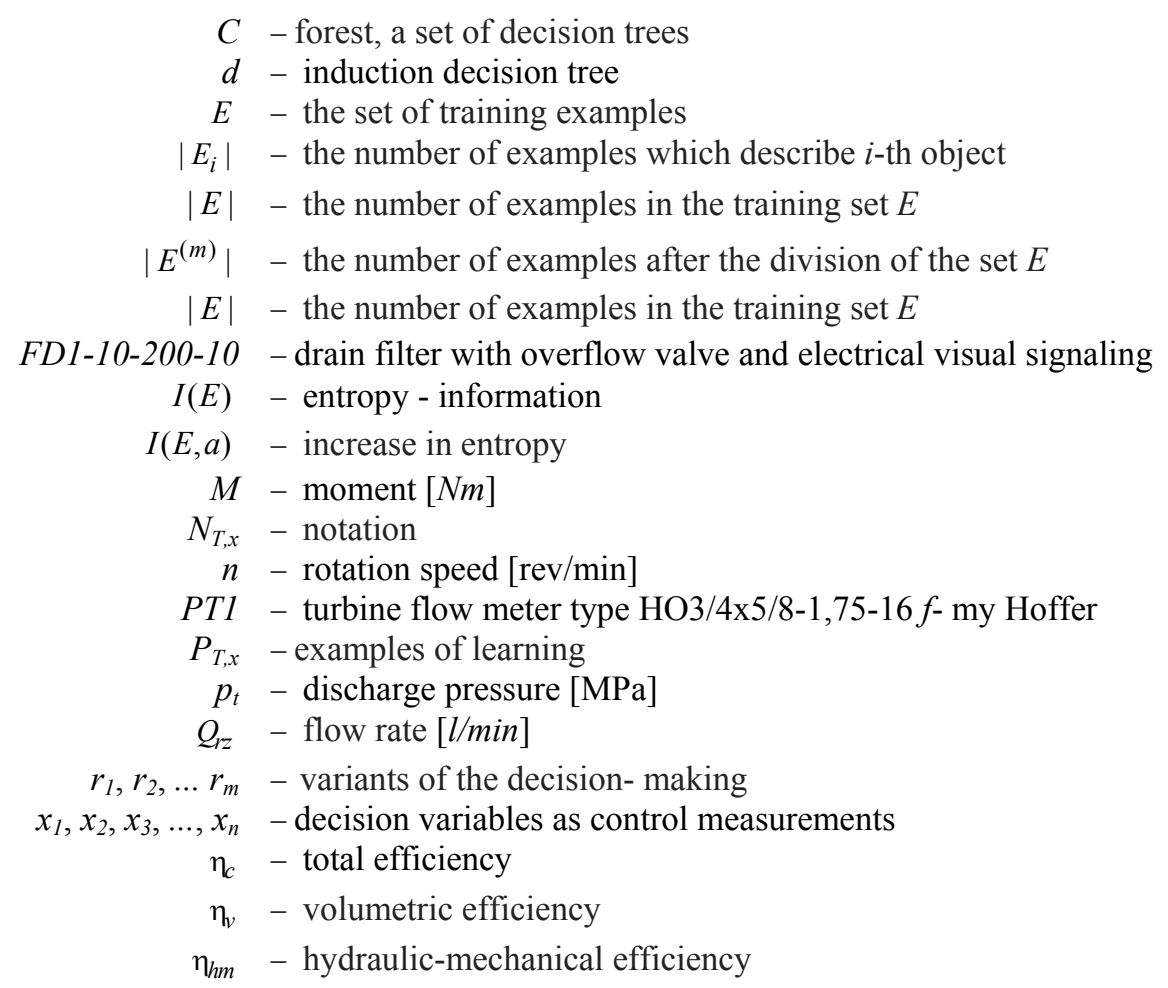

\section{References}

[1] Abel F. (1971): Johannes Kepler and his importance to modern science. - Inter Nations Bonn - Bad Godesberg.

[2] Stryczek J. and Stryczek S. (1994): Gear pumps - a brief history. - SINH. Control and Hydraulic Drive.

[3] Stryczek S. (1996): Two hundred years of hydrostatic driver. - Control and Hydraulic Drive.

[4] Kollek W. and Osiński P. (2009): Modelling and design of gear pumps. - Wroclaw University of Technology Press.

[5] Kollek W. and Radziwanowska U. (2015): Energetic efficiency of gear micropumps. - Archives of Civil and Mechanical Engineering, vol.15, No.1, pp.109-115.

[6] Kollek W., Osiński P., Stosiak M., Wilczyński A. and Cichoń P. (2014): Problems relating to high-pressure gear micropumps. - Archives of Civil and Mechanical Engineering, vol.14, No.1, pp.88-95.

[7] Osiński P., Deptuła A. and Partyka M.A. (2013): Discrete optimization of a gear pump after tooth root undercutting by means of multi-valued logic trees. - Archives of Civil and Mechanical Engineering, vol.13, No.4, pp.422-431.

[8] Osiński P. (2014): Modelling and design of gear pumps with modified tooth profile. - Saarbrücken, LAP Lambert Academic Publishing.

[9] Osiński P. (2013): High and low pulse gear pumps external gear. - Wroclaw University of Technology Press.

[10] Stryczek S. (1995): Hydrostatic Drive. - Warsaw: Scientific and Technical Publishing House. 
[11] Kudźma S. and Kudźma Z. (2015): Refined model of passive branch damper of pressure fluctuations. - Journal of Theoretical and Applied Mechanics, vol.53, No.3, pp.557-567.

[12] Osiński P. and Kollek W. (2013): Assessment of energetistic measuring techniques and their application to diagnosis of acoustic condition of hydraulic machinery and equipment. - Archives of Civil and Mechanical Engineering, vol.13, No.3, pp.313-321.

[13] Osiński P., Kollek W. and Wilczyński A. (2010): The use of a series of Renard in the design of hydraulic and pneumatic components. - Hydraulic and Pneumatic, No.6, pp.16-18.

[14] Śliwiński P. (2014): Flow of liquid in flat gaps of the satellite motor working mechanism. - Polish Maritime Research, 2(82), vol.21, pp.50-57.

[15] Deptuła A. (2015): Application of game graphs to describe the inverse problem in the designing of mechatronic vibrating systems, Graph-based modelling in engineering. - Springer, [In print].

[16] Partyka M.A. (1983): Some remarks on the Quine - Mc Cluskey minimization algorithm of multiple-valued partial functions for design structures. - 7th Inter. Cong. Log. Method. Phil. Sc., Salzburg, Austria.

[17] Partyka M.A. (1984): The Quine- Mc Cluskey minimization algorithm of individual multiple- valued partial functions for digital control systems. - 3rd Inter. Confer. Syst. Engin., Wright State University, Dayton, USA.

[18]Quine W.V. (1952): The problem of simplifying truth- functions. - American Mathematical Monthly, vol.59, pp.521- 531 .

[19] Deptuła A. and Partyka M.A. (2012): Separate logical analysis of design guidelines in the machine systems modelling. International Journal of Applied Mechanics and Engineering, vol.17, No.3, pp.779-790, ISSN 1425-1655.

[20]Deptuła A. (2014): Application of multi-valued weighting logical functions in the analysis of a degree of importance of construction parameters on the example of hydraulic valves. - International Journal of Applied Mechanics and Engineering, vol.19, No.3, pp.539-548.

[21]Berghofer S. and Reiter M. (2009): Formalizing the Logic-Automaton Connection. - In: Proc. of the 22nd International Conference on Theorem Proving in Higher Order Logics, LNCS No 5674, pp.147-163.

[22] Shiue Y.R. and Guh R.S. (2006): The optimization of attribute selection in decision tree-based production control systems. - The International Journal of Advanced Manufacturing Technology, vol.28, pp.737-746.

[23] Shenoy P.P. (1998): Game Trees For Decision Analysis. - Theory and Decision, vol.44, No.2, April, pp.149-171.

[24] Deptuła A. and Partyka M.A. (2013): Discrete optimization of a gear pump after tooth undercutting by means of complex multi-valued logic trees. - Innovations in Management and Production Engineering, Oficyna Wydawnicza Polskiego Towarzystwa Zarządzania Produkcją, Opole, ISBN: 978-83-930399-9-9, pp.175-186.

[25] Deptuła A. (2014): Game- tree structures with the complex complexity level as a tool in knowledge engineering. Systems in Management, vol.2, No.2, pp.100-112.

[26] Deptuła A. and Partyka M.A. (2014): Decision optimization of machine sets with taking into consideration logical tree minimization of design guidlines. - International Journal of Applied Mechanics and Engineering, vol.19, No.3, University Press Zielona Góra, pp.549-561.

[27] Deptuła A., Osiński P. and Radziwanowska U. (2016): Decision support system for identifying technical condition of combustion engine. - Archives of Acoustics, vol.41, No.3, pp.449-460 [in print].

[28] Deptuła A., Kunderman D., Osiński P., Radziwanowska U. and Włostowski R. (2016): Acoustic diagnostics applications in the study of technical condition of combustion engine. - Archives of Acoustics, vol.41, No.2, pp.345-350. 